\title{
EL PASO DEL TIEMPO EN LA HISTORIA DE LA LENGUA. (EL ORIGEN DE LAS LENGUAS. BIOLOGÍA Y LINGÜÍSTICA) ${ }^{1}$
}

\section{Julio Sánchez Hernández}

Comento las teorías de Merritt Ruhlen que, apoyándose en las familias de lenguas y en las superfamilias ya estudiadas, intenta acercarse a la lengua primigenea y deduce 27 raíces universales presentes en un número importantes de familias de lenguas del mundo. Recojo, a su vez, las investigaciones de Cavalli-Sforza sobre la genética humana, sus observaciones sobre la relación entre los grupos genéticos humanos y las familias de lenguas y la cronología de la dispersión del hombre moderno desde el probable hogar africano hasta ocupar toda la tierra, que contribuyen a respaldar las teorías de Ruhlen.

I will comment on the theories of Merritt Ruhlen. He assumes the existence of a family of languages and macrofamilies and attempts to approach the first language. He deduces that there are 27 universal roots which are in a large number of families of languages of the world. At the same time I will keep in mind the investigations of Cavalli-Sforza about the human genetics, his observations about the relationships between the human genetical groups and the family of languages, his opinions about the possible dispersions of the modern man from their probable African home to the occupation of the whole earth and the way they contribute to back the theories of Ruhlen.

\section{LA FAMIILIA LINGÜÍSTICA.}

Desde que el hombre ha sido consciente del fenómeno del lenguaje se ha preguntado por el origen de la lengua y la relación de su lengua con las de los vecinos.

Hoy existen en la tierra entre 3000 y 5000 lenguas, la mayoría habladas por muy pocas personas.

Hasta ahora los lingüistas agrupaban las lenguas del mundo en familias, así el castellano, catalán, portugués, etc. provienen del latín. El latín, griego, celta, lenguas eslavas, germanas, etc., etc., provienen del indoeuropeo.

La clasificación de las lenguas en familias reposa sobre el descubrimiento de que en lenguas diferentes hay palabras que se parecen a la vez por su significante y su significado. El parecido se puede deber a convergencia, préstamo o al origen común.

\footnotetext{
${ }^{1}$ Seguiré esencialmente las teorías de Merritt Ruhlen en On the Origin of Languages. Studies in Linguistic Taxonomy, Stanford University Press, Standford, 1994 y de Luigi Luca Cavalli-Sforza en Genes, pueblos y lenguas, Drakontos, Critica, Barcelona 1997, cuyo resumen apareció en Investigación y Ciencia, número 184, Enero de 1992, pp. 4-12.
} 
Podemos clasificar las lenguas de no importa que región del mundo en familias perfectamente evidentes según sus parecidos léxicos y gramaticales debidos a su origen común.

Así las 3000 o 5000 lenguas del mundo son agrupadas en trescientas o cuatrocientas familias. Como vemos una simplificación importante.

\section{LA SUPERFAMILIA. El NOSTRÁtico.}

Por desgracia algunos lingüistas se sienten inseguros al ir más allá del nivel de familia lingüística.

Se trata en definitiva de continuar la cadena. El español tiene lenguas hermanas, que derivan todas de un antepasado común, el latín, que a su vez tiene lenguas hermanas como el griego, el sánscrito, el germánico, el eslavo, todas las cuales derivan de una lengua común que es el indoeuropeo. Parece legítimo preguntarse si el indoeuropeo tenía lenguas hermanas, cuáles eran y cuándo se habló la lengua común más antigua de las que ellas derivaron.

Se ha intentado establecer entre algunas familias lazos de parentesco más lejanos y se ha fijado con aceptación alguna superfamilia.

El indoeuropeo ha sido relacionado con el sumerio, el ainú y las lenguas semíticas. Ya en el siglo pasado Pedersen intentó reunir en una macro familia a indoeuropeos, semitas, camitas, urálicos, altaicos, yukagir y esquimales y además le dio nombre. Basándose en la analogía del nombre que los romanos daban al Mediterráneo (Mare Nostrum) Pedersen pensó en la Lingua Nostra, de donde extrajo el término Nostrático, que hoy se ha impuesto.

El método cronológico ha demostrado su eficacia para el estudio de la familia de las lenguas indoeuropeas, de las semíticas, etc. pero tiene limitaciones, sobre todo cronológicas. Su validez, su aplicabilidad están circunscritas a unas determinadas coordenadas espacio-temporales. O si se prefiere, a unos determinados niveles de parentesco.

Hablar de parentesco entre las lenguas es una metáfora y no debe entenderse literalmente, a pesar de lo cual sigue siendo útil el empleo de la terminología de familia.

Deberemos distinguir un parentesco próximo, existente entre lenguas cuyo antepasado común se hablaba hace entre 1500 y 2500 años, este es el caso del latín y el germánico. Parentesco medio, con un antepasado común hablado hace 6.000 o 6.500 años, las lenguas indoeuropeas y las semíticas por ejemplo. Y el parentesco lejano, para las lenguas cuyo antepasado común se habló hace 10.000 años o más.

Pues bien, el método comparativo, que ha dado sus grandes frutos en el ámbito del parentesco próximo y medio, se revela bastante menos conclusivo en el del parentesco remoto.

Y ahí está la aporía. Ningún lingüista negaría la existencia de parentescos remotos entre las lenguas. Ninguno dudaría de que el indoeuropeo, o el semítico, o el urálico, hubieron de tener parientes. Muy pocos vacilarían en reconocer el enorme interés que un conocimiento preciso de estos parentescos remotos ofrecerían para penetrar más profundamente en la prehistoria de los pueblos indoeuropeos en particular y de la Humanidad en general. Sin embargo, son muy pocos los que estarían dispuestos a embarcarse en la aventura científica en la que se sienten carentes del instrumento adecuado para obtener resultados rigurosos. 
Una segunda dificultad que obstaculiza el desarrollo de este ámbito de la lingüística histórica comparativa es su propia complejidad intrínseca. Ya es ardua la labor del indoeuropeísta, que ha de conocer decenas de lenguas cuyo manejo es imprescindible en la comparación. Pero un nostratista ha de trabajar no ya con decenas sino con centenas de lenguas del más variado cuño, que pueden ir desde el hebreo al dravídico, del japonés al lapón o del turco al eslavo antiguo.

El bagaje de conocimientos previos que se necesitan hacen la profesión de nostratista inasequible para la mayoría de los lingüistas. Y en estas dos circunstancias- debilidad de método en distancias tan lejanas y dificultad de adquisición de centenares de lenguas- están las claves del estancamiento del estudio de esta especialidad.

Se interesaron en el nostrático Illich -Svitych y A.B. Dolgopolsky quienes trabajando separadamente llegaron a conclusiones similares a mediado de los años 60. Según estos autores el indoeuropeo pertenecía a la misma familia lingüística que el afroasiático (semítico, egipcio antiguo, berebere), urálico (finlandés húngaro, samoyedo), altaico (turco, mongol, japonés, coreano), kartvélico (es decir, caucásico meridional: georgiano, svano, zano) y dravídico (telegú, tamil, kannada). El antepasado común de esta familia sería el nostrático, que habría sido hablado en el oriente medio hacia 12.000-15.000 a. de C. Sus hablantes se habrían desparramado desde allí hasta ocupar casi toda Eurasia y una parte de África.

Illich Svitich murió prematuramente en 1966 cuando contaba sólo con 32 años. Dolgopolsky emigró a Israel pero los estudios de nostrático han continuado con alumnos de ambos.

Un importante problema que ha afrontado estos estudios es el de distinguir las palabras patrimoniales comunes en todas las lenguas nostráticas de las coincidencias debidas a préstamo entre ellas. En efecto, la convivencia durante milenios entre unas y otras ha hecho que los préstamos cruzados sean una verdadera maraña en la que resulta muy difícil hacerse camino.

Dolgopolsky ha establecido una lista de palabras que nunca o rara vez se prestan de unas lenguas a otras. Las palabras más estables, en orden descendente de resistencia al préstamo serían: yo/ me, dos / par, tú, qué / quién, lengua, nombre, ojo, corazón, diente, no, uña, llanto, agua, muerte, luna, mano, noche, sangre, cuerno, lleno, sol, oreja, sal.

Los estudios sobre parentescos remotos han continuado en los años siguientes. Shevoroshkin desde Norteamérica avanza un paso más y opina que pueden encontrarse indicios de que la mayor parte de las lenguas conocidas de la humanidad tienen un origen común. Todas podrían pertenecer a una lengua ancestral hablada hace 25.000 o 30.000 mil años.

Esta superfamilia nostrática ha sido aceptada con algunas variantes por el lingüista americano Greenberg. Él la llama Euroasiática, abarca un área un poco más reducida y no incluye la familia afroasiática ni la dravídica.

Intentar saber cómo eran las lenguas de esas superfamilias y reconstruirlas es una tarea mucho más difícil, en alguna medida casi imposible.

La evolución lingüística es muy rápida. El paso del tiempo es responsable de cambios de todo tipo: fonéticos, semánticos y gramaticales que pueden ser muy grandes. Bajo la presión de cambios rápidos una lengua llega a ser incomprensible en un plazo bastante corto. Tras una separación de 5.000 ó 10.000 años las palabras que muestran un parentesco 
se reducen a un 10 o un $20 \%$. Y con un análisis superficial parece que las lenguas más alejadas no tienen ningún parecido entre sí.

\section{RAÍCES COMUNES. LA LENGUA MADRE.}

Por suerte algunas palabras poseen una velocidad evolutiva más lenta y facilitan la reconstrucción de parentescos lejanos.

Por ejemplo el lingüista norteamericano Greenberg, destacó que por lo menos hay una etimología común a todas las familias lingüísticas: se trata de la raíz TIK, que puede indicar ya sea dedo, ya sea el número uno (una variación semántica que no necesita ser explicada, si pensamos en la forma de indicar el número 1 con un gesto). En alguna lengua se encuentran otros cambios semánticos que todavía parecen aceptables, como mano o brazo.

En indoeuropeo dedo sería deig, emparentado con deik: "mostrar", "pronunciar solemnemente". En latín dedo será digitus "el que indica". De aquí derivarán palabras como decir, dicción, adicción, bendecir, dictar, dictador, abdicar, predicar, etc.

Partiendo de este ejemplo los lingüistas estadounidenses Bengtson y Ruhlen han propuesto veintisiete raíces universales o casi universales. Desgraciadamente el número de palabras que no cambian, con las que se puede contar para estas indagaciones es muy limitado. Por lo general son palabras que indican las partes del cuerpo, pronombres personales, algún que otro adverbio, los números uno, dos, tres, y pocas más ${ }^{2}$.

Reproduzco las raíces universales con algunas palabras de lenguas conocidas sorprendentemente similares ${ }^{3}$.

Aja: madre o la mujer mas anciana de la familia.

Aq'wa: agua (latín agua, germánico aha: río pequeño).

Bun(n)ka: rodilla, doblar (inglés bow, elbow).

Bur: polvo, ceniza.

Cun(g)a: nariz, oler.

Kama: coger en la mano.

Kano: brazo (inglés hand).

Kati: hueso (latín costa, castellano costilla).

K'olo: agujero (inglés hole).

Kuan: perro (griego kuo:n, latín can, is, alemán Hund)

$\mathrm{Ku}(\mathrm{n})$ quien (inglés who?, castellano ¿quién?)

Kuna: mujer.

Mako: niño (antiguo irlandés mac: hijo de).

Maliq’a: chupar, succionar, pecho (inglés milk, alemán Milch, melken : ordeñar)

Mana: permanecer en un lugar (inglés to remain).

Mano: hombre (inglés man, alemán Mann).

Mena: pensar (latín men(s), memeini: recordar, castellano memento, mente.

Mi(n): ¿qué?.

Pal: dos.

Par: volar.

Poko: brazo (inglés bough).

Puti: vulva (latín puta: chica, castellano puta).

Teku: pierna, pie.

\footnotetext{
${ }^{2}$ Es significativo que las palabras mejor conservadas a lo largo de la evolución lingüística sean las que primero se aprenden: La madre enseña al hijo ojos, nariz, boca, etc.

${ }^{3}$ Merrit Ruhlen, op. cit. pp. 292-328.
} 
Tik: dedo, uno (latín dig(itus): dedo).

Tika: tierra

Tsaku: pierna, pie.

Tsuma: pelo (vasco zam-ar(r): rizo de pelo o lana, castellano zamarra).

Las veintiséis raíces mundiales están representadas al menos en seis familias, pero la mayor parte de ellas están representadas al menos en doce familias y la más extendida $\mathrm{KU}(\mathrm{N})$, "quien" está representada en veintitrés o veinticuatro familias.

Estas opiniones sobre las raíces universales son el apoyo más claro a su hipótesis sobre el origen único de las lenguas del mundo. Se trata de 27 raíces mundiales, es decir 27 palabras existentes por numerosas familias lingüísticas y de las que no se puede explicar su parecido más que por el hecho de que ellas hayan formado parte de la lengua original común y que ha debido ser hablada por nuestros antepasados hace 50.000 años.

Estas raíces no son reconstrucciones. Su forma fonética y el valor semántico son "etiquetas" que sólo indican una primera aproximación a la que podría haber sido el original de la palabra concerniente. Su validez proviene de las palabras manifiestamente emparentadas sobre las cuales reposan estas etiquetas.

No se comparan el conjunto de las lenguas del mundo tomadas del montón sino de treinta y dos familias de lenguas del mundo ya conocidas y admitidas por los lingüistas. Esto significa que sólo las palabras consideradas como integrantes del vocabulario original común de cada lengua (o sea, las mismas palabras sobre las que se fundamentan la validez de esas treinta y dos familias lingüísticas) han sido admitidas en la comparación.

Las 27 raíces que siguen están presentes en al menos seis de estas familias, pero como media una raíz está representada en 12 familias y la más extendida ku(n) "quién" está representada en 24 grandes familias.

Siempre escogieron familias lingüísticas de bajo nivel como el indoeuropeo, la familia mongola, la familia turca y no superfamilias como la nostrática o la euroasiática sobre todo para insistir que no es indispensable elaborar todos los estadios intermedios para intentar los agrupamientos de alto nivel.

El caso del indoeuropeo es claro, primero se reconoció la existencia del grupo y luego se fueron reconstruyendo los niveles intermedios de evolución, tarea que está inacabada aún hoy en día. Es un lugar común en taxonomía que los niveles más elevados de la clasificación son frecuentemente más evidentes y más fáciles de demostrar que niveles inferiores. Para estos autores es muy fácil demostrar que todas las lenguas del mundo están emparentadas a la vista de las raíces presentadas. Descubrir los agrupamientos intermedios de las lenguas es una tarea mucho más difícil. El amerindio es un grupo lingüístico bien definido pero la determinación de grupos intermedios es mucho más difícil.

Existe, por tanto, una masa de elementos comunes para todas las lenguas del mundo, de signos lingüísticos que se parecen en las lenguas y las familias de lenguas que no puede explicarse racionalmente más que admitiendo que reflejan una unidad anterior.

No se puede probar en el sentido matemático del término que todas las lenguas del mundo estén emparentadas pero la pequeña cantidad de parecidos lingüísticos presentados sugieren un origen común de todas las existentes.

Probar es un concepto matemático que no tiene aplicación en las ciencias empíricas tales como la lingüística. En estos dominios del saber no se intenta tanto probar una cosa como dar una explicación lo más verdadera posible a una serie no aleatoria de hechos. 


\section{Pruebas de otras CienCias. Genética.}

Lo sorprendente es que otras ciencias hayan acudido en ayuda de la lingüística y sostengan la teoría. Los conocimientos que tenemos de la genética y de la prehistoria nos llevan a la misma conclusión

Reuniremos, por tanto, tres tipos de argumentos: los lingüísticos, los genéticos y los arqueológicos.

Las conclusiones de Ruhlen por revolucionarias que sean no desatarían más que especulación intelectual y curiosidad histórica si no coincidieran con otros descubrimientos recientes salidos de la ciencia de la genética de la población en la que trabajan el japonés Takahata y el nipón-americano Nei.

Durante la evolución, el ADN de todos los organismos sufre pequeños cambios que se acumulan progresivamente. La cantidad de cambios de un individuo o una especie respecto a otra depende de cuánto tiempo lleve evolucionando por separado, o sea, acumulando diferencias en sus ADN.

Sus estudios sobre nuestro código genético, las secuencias del $\mathrm{ADN}$ que han transportado a través de los tiempos el esquema de organización del ser humano demuestran: que todos los seres humanos procedemos de los mismos antepasados, el Homo Sapiens-Sapiens en un periodo muy cercano, entre 150.000 y 100.000 años independiente de nuestra talla, color o tipo de cara .

Algunos trabajos demuestran que esos antepasados debieron de pasar hace 60.000 años por un descenso demográfico y sus efectivos habrían caído hasta los 30.000 individuos y de ese pequeño grupo descenderíamos todos.

Estos 30.000 individuos debieron vivir en un área relativamente reducida y según las pruebas aportadas por la prehistoria debió ser entre el norte y el este de África y el Próximo Oriente según los fósiles conocidos. O sea entre lo que hoy es Somalia y la Península Arábiga ${ }^{4}$.

Esta teoría es perfectamente compatible con las variaciones físicas que vemos en las razas actuales. Las clasificaciones de razas al uso se basan en características externas: estatura, color de piel, pelo y ojos, forma del cráneo, etc.

Los caracteres étnicos evolucionan con gran rapidez bajo la acción de los factores ambientales. Por ejemplo, los japoneses han crecido $20 \mathrm{~cm}$ en dos generaciones y los indios de la Patagonia son de piel mucho más clara que los de Venezuela o Méjico aunque cuando penetraron en América eran el mismo grupo humano. El color de la piel está determinado por la intensidad solar y, en general, por el clima.

El medio también puede modificar la base genética a largo plazo, a través de la selección natural. Los caracteres somáticos sólo reflejan las condiciones ambientales que conocieron estas poblaciones del periodo más reciente.

Otra prueba más remacha esta teoría. Recientemente se ha obtenido material genético $(\mathrm{ADN})$ de los restos del Hombre de Neandertal. Su análisis indica que el hombre moderno no procede del de Neandertal sino que evolucionó a partir de otros homínidos.

\footnotetext{
${ }^{4}$ Hasta ahora para algunos, las familias lingüísticas eran independientes unas de otras y correspondían a adquisiciones diferentes de la facultad de hablar de los hombres prehistóricos. Pero esto es imposible, 30.000 hombres de una sola población biológica no pueden hablar 200 o 400 lenguas de orígenes diferentes.
} 
El trabajo, producto de la colaboración de paleontólogos y biólogos moleculares de Alemania y Estados Unidos, se inició a partir de un trozo de hueso del hombre de Neandertal.

El fragmento de $\mathrm{ADN}$ obtenido fue comparado con los fragmentos equivalentes del $\mathrm{ADN}$ humano y del $\mathrm{ADN}$ del chimpancé, la especie viva evolutivamente más cercana al hombre.

Estas comparaciones se basan en que durante la evolución, el $\mathrm{ADN}$ de todos los organismos sufre pequeños cambios que se acumulan progresivamente. $\mathrm{La}$ cantidad de cambios de una especie respecto a otra depende de cuánto tiempo lleve evolucionando por separado, o sea, acumulando diferencias en sus $A D N$. Esto nos puede dar una idea de cuándo apareció una especie. El fragmento de $\mathrm{ADN}$ del chimpancé presentó una media de 55 cambios respecto al humano, mientras que el fragmento del hueso del hombre de Neandertal presentó una media de 27 cambios. Las diferencias entre el ADN de las distintas especies se puede además cuantificar en años. El registro fósil indica que la línea que dio lugar a los chimpancés y la que dio lugar a los humanos se separaron hace entre cuatro y cinco millones de años, tiempo en el que sus respectivos fragmentos de $\mathrm{ADN}$ acumularon los 55 cambios mencionados antes. Las 27 diferencias que se encontraron entre el fragmento del ADN del hombre de Neandertal y el humano indican que ambas líneas debieron separase hace entre 550.000 y 690.000 años. Sin embargo todos los hombres actuales presentan entre sí una media de sólo ocho cambios en el ADN. Esto significa que el hombre moderno se originó mucho más recientemente, hace como máximo entre 120.000 y 150.000 años, y que, además, lo hizo a partir de una pequeña población genéticamente distinta de la Neandertal.

Aunque estas dataciones son aproximadas y a veces discutibles, y aunque todos los resultados se basan en los restos de un individuo Neandertal analizado, las conclusiones apuntan en la misma dirección que otros datos independientes recabados en los últimos años ${ }^{5}$.

La hipótesis actual más aceptada propone, por tanto, que el hombre moderno (Homo Sapiens) -y por tanto su lengua- se originó en África hace alrededor de 150.000 años y que desde allí se extendió por el resto del mundo reemplazando y sin llegar a mezclarse con otros homínidos (entre ellos al Homo Neanderthalensis, que vivía en Europa, Asia Central y Oriente Próximo y al Homo Erectus de la Isla de Java,) hasta convertirse hace 20.000 años en el único hombre que habitaba la tierra ${ }^{6}$.

Por tanto, el origen de nuestras lenguas tiene que ir unido exclusivamente al Homo Sapiens y la diversidad y diferenciación de las lenguas tiene como máximo la misma antigüedad del Homo Sapiens.

\section{Pruebas de otras ciencias. Arqueología.}

Los datos arqueológicos coinciden sorprendentemente con los de la biología: el homo antecesor debió vivir sobre el 750.000 de él descenderían el Homo Neanderthalensis ${ }^{7}$, que

\footnotetext{
${ }^{5}$ Recuperar el ADN de un organismo fósil resulta mucho más difícil de lo que el autor de Parque Jurásico se imaginó. Sobre todo porque se duda de que existan en la naturaleza condiciones que permitan la conservación de $\mathrm{ADN}$ de más de 100.000 años.

${ }^{6}$ El País/ Sociedad, miércoles 3 de septiembre de 1997 p. 28, artículo de Rafael Flores.

${ }^{7}$ Eran más bien bajos y muy robustos. Relativamente civilizados, conocían el fuego y practicaban enterramientos.
} 
vivió desde el 500.000 hasta el 20.000, desapareciendo después, y el Homo Sapiens, que sería el Cromagnon ${ }^{8}$, que apareció, según los restos arqueológicos, hace entre 90.000 y 120000 años.

\section{RELACIÓN DE LA GENÉTICA Y LA FAMILIA LINGÜÍSTICA.}

Pero no es sólo que todos los seres humanos provengamos de un pequeño grupo de los mismos antepasados en una fecha cercana sino que los descubrimientos más recientes de genética de las poblaciones humanas muestran que hay una coincidencia entre la diversidad genética de la población y su diversificación lingüística. O sea que la variación frecuente de genes sobre la superficie de la tierra se corresponde con la subdivisión en grandes grupos lingüísticos. Y como no son los genes lo que determina la lengua que se habla ni las lenguas lo que determinan los genes, si los dos fenómenos evolucionan de manera paralela tienen un sintonizador común. Hay por tanto una relación entre genes y lenguas.

La explicación al paralelismo en la evolución entre la genética y lengua es sencilla. El aislamiento debido a barreras, de cualquier tipo impide el matrimonio entre dos poblaciones y por tanto el intercambio genético. Entonces las poblaciones evolucionarán independientemente y se volverán distintas. La diferenciación genética aumentará regularmente con el paso del tiempo. Lo mismo sucede desde el punto de vista lingüístico: el aislamiento reduce o anula los intercambios culturales y las lenguas también se diferencian. "Por lo tanto tiene que haber una correspondencia básica entre el árbol lingüístico y el árbol genético, pues reflejan la misma historia de separaciones y aislamientos evolutivos".

Comparación entre las familias lingüísticas y el árbol genético ${ }^{10}$.

\footnotetext{
${ }^{8}$ Traerán nuevas técnicas de hacer herramientas, unos milenios después manifestaciones artísticas, arte rupestre, vida social más refinada, más compleja, y por tanto lengua más abstracta, más rica y evolucionada.

9 Luca Cavalli-Sforza, op. cit. p. 155.

${ }^{10}$ Luca Cavalli-Sforza op. cit. p. 147.
} 
Arbol genético Poblaciones

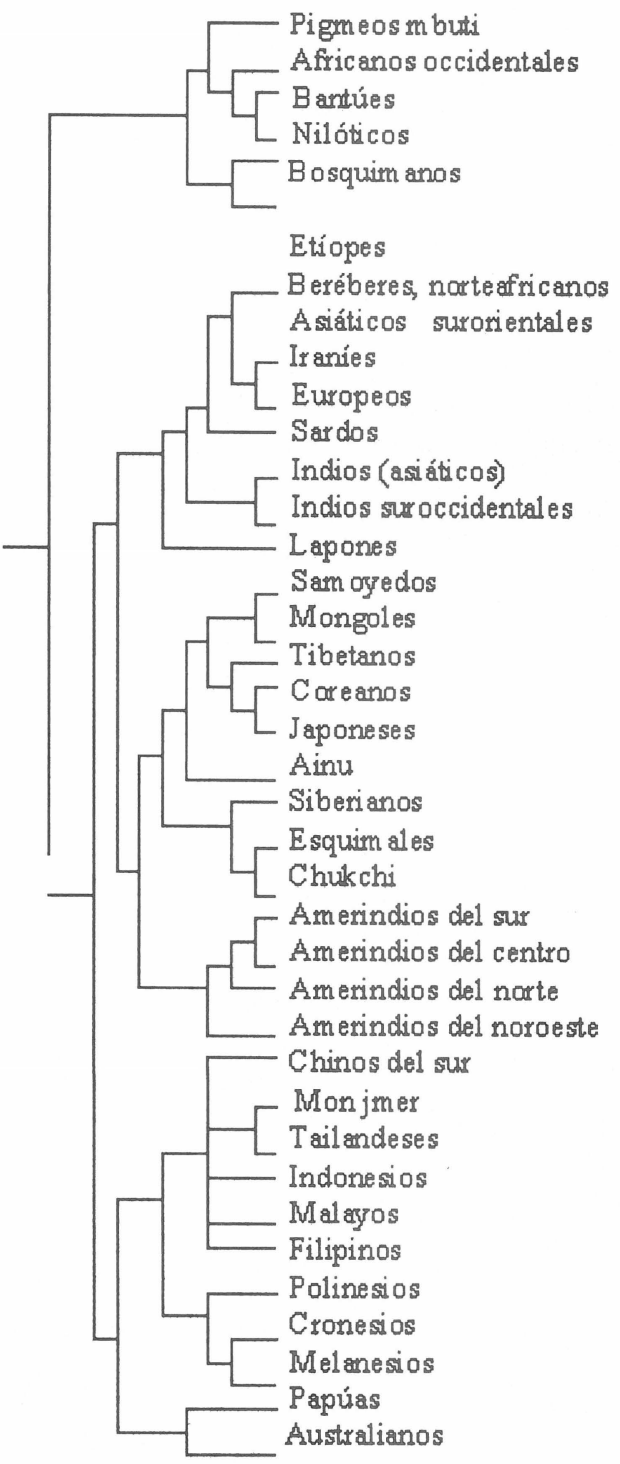

Familias

Súper

Lingüisticas

Familias

lengua original desconocida

niger-k or dof ana

แ 4

nilosahariana

khoisánida

afroasiática

« 4

« «

indoeuropea

st

ss

66

dravídica

ứálica- yrukaghir

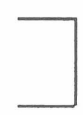

Congo-

Saharianas

altaica

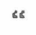

46

s

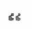

«

esquim al eutina

chukchi-k am chatk a

am erindia

s6

๘6

na-dené

sinotibetana

austrasiática

daica

austronesia

s6

6

s6

«

indopacifica

$\triangle 6$

australiana
Euroasiática

y 0 nostrática
Austrica 
Encontramos 5 grandes grupos humanos según el árbol genético. El primero agrupa a pueblos del África subsahariana y coincide en buena medida con la superfamilia lingüística congo-sahariana.

El segundo agrupa a pueblos de Europa, Norte de África, Oriente Medio y el subcontinente indio. Coincide con las familias Afroasiática, Indoeuropea y Dravídica.

El tercero agrupa a pueblos de Oriente Lejano y Siberia.

El segundo y tercer grupo forma la gran súper familia Euroasiática o Nostrática.

El cuarto, muy próximo al tercero, engloba a los aborígenes americanos y casi todas sus lenguas forman la familia de Amerindia.

El quinto agrupa a los pueblos del sur de Asia, a los aborígenes australianos y habitantes de las islas del Pacífico.

Como vemos se produce una bifurcación en el árbol genealógico de la humanidad entre los africanos subsaharianos y los otros seres humanos y datan esta separación en algo menos de 100.000 años. La localización en África de la división primaria de este árbol genealógico incide a favor de la teoría del hogar africano de la especie humana actual, pues encontramos la mayor diferencia en las regiones más antiguamente pobladas y en las cuales las variaciones genéticas han tenido más tiempo para aparecer y acumularse. Por otra parte en África los arqueólogos han descubierto los fósiles más antiguos de hombres de nuestra especie, y de los objetos a los que lo asociamos.

Como vemos también algunos grandes agrupamientos coinciden con las familias lingüísticas de alto nivel.

La correlación entre lenguas y genes no es perfecta porque las conquistas rápidas de las grandes regiones pueden ocasionar que unas lenguas sean reemplazadas por otras no emparentadas con ellas. Pero estos fenómenos no parecen tan frecuentes como para hacer que desaparezca la correlación.

Aunque no existe un árbol evolutivo completo de las familias lingüísticas ya podemos comparar el árbol genético con lo que conocemos del árbol lingüístico, aunque el árbol de las lenguas es incompleto vemos que los parecidos son impresionantes. A una familia muchas veces le corresponden una, dos, tres e incluso más ramas del árbol genético, otras veces una sola rama.

No obstante hay excepciones a la regla de que las familias lingüísticas comprenden siempre poblaciones muy próximas en el árbol genético. Por ejemplo los etíopes forman parte de la rama genética africana pero hablan lenguas de la familia afroasiática, que está muy difundida en el norte de África, Arabia y Oriente próximo, es decir poblaciones que son de raza blanca.

Otra excepción de esta clase son los lapones, que genéticamente forman parte de los caucasoides pero hablan una lengua de la familia urálica cuyos representantes más típicos se encuentran en el noreste de Rusia y en el noroeste de Siberia. Las poblaciones urálicas de Asia son genéticamente mongoloides y los lapones son una mezcla de escandinavo y mongoloides de origen siberiano en que prevalece el primer componente. Tanto en el caso de los lapones como en el de los etíopes la explicación es bien sencilla: las dos poblaciones derivan de mezclas genéticas de tipo europeos-siberianos los primeros y africano-árabe los segundos. Las mezclas genéticas tienden a reproducir exactamente las proporciones de las dos poblaciones ancestrales. Pero las poblaciones genéticamente mixtas tienden a mantener una sola de las dos lenguas de las poblaciones de origen, aunque la lengua que desaparezca 
influya más o menos en la que prevalece, efecto que se conoce como fenómeno de substrato.

Es evidente que lapones y etíopes estuvieron durante miles y miles de años en contacto con sus vecinos y recibieron de ellos lenta y continuadamente una gran influencia genética.

Cuando el contacto genético entre los pueblos es prolongado durante un largo periodo, las lenguas preservan una imagen más clara del estado anterior mucho mejor que sus genes. Otro ejemplo lo tenemos con la lengua vasca que es hoy completamente distinta de la de sus vecinos; los genes vascos no lo son. Porque las lenguas no se mezclan de la misma manera que los pueblos.

Una reconstrucción de la historia genética y lingüística del mundo tiene que ser necesariamente incompleta, porque hoy por hoy quedan numerosas lagunas y zonas dudosas.

Hay una importante analogía entre la evolución de los genes y la de las lenguas. Pero tiene que quedar claro que no existe ningún motivo para pensar que los genes influyan en la posibilidad de hablar una lengua u otra. El hombre posee, desde su nacimiento, la capacidad de aprender cualquier lengua conocida. La estructura de todas las lenguas modernas tiene una complejidad comparable y las lenguas de los grupos étnicos que viven en un nivel económico primitivo no son más primitivas que la nuestra

\section{EXPANSIÓN Y SEPARACIÓN LINGÜÍSTICA DEL HOMBRE POR EL MUNDO.}

Según todo esto la expansión del hombre por el mundo y la expansión y dispersión de su lengua debió de ser más o menos así.

Desde el noreste de África parte una expansión en una época sin precisar, quizás hace 60.000 años. Sigue la costa meridional de Asia. Del sureste de Asia parten dos ramas: hacia el norte, Vietnam, China; hacia el sur, Nueva Guinea y Australia, siempre por la costas.

Continuación de la navegación a lo largo de la costa oriental de Asia hacia el norte; el movimiento de poblaciones hacia el interior origina las poblaciones del noreste asiático: chinos del norte, coreanos, japoneses, mongoles, etc., etc.

Primer paso por el estrecho de Bering y comienzo del poblamiento de América, hace entre 50.000 y 30.000 años. Quizás por tierra firme, quizá costeando.

Entre el 50.000 y 30.000 comienza el poblamiento de Asia Central y Asia del norte, a partir del este de Asia.

Entre el 45.000 y el 40.000 comienzo del poblamiento de Oriente Próximo a partir del sur de Asia, del norte y del este de África.

Hace 40.000 años comienzo del poblamiento de Europa desde Oriente próximo y del Asia central y de América desde el noreste asiático.

Bien es cierto que algunas conclusiones son provisionales, algunas opiniones muy discutible. Se necesitará mucho tiempo aún para que la genética, la arqueología, la paleontología y la lingüística se pongan de acuerdo para contar en los mismos términos la gran historia del hombre. Pero cuanto más avanza la ciencia más cuerpo toma la idea de que el género humano es uno y de que todas las lenguas humanas pueden tener el mismo origen en un pasado no demasiado lejano. 